\title{
The Effect of Different Fibre Length and Different Urea Formaldehyde (UF) content on Sound Absorption Performance of Empty Fruit Bunch (EFB)
}

\author{
Ida Norfaslia Nasidi $^{1 *}$, Lokman Hakim Ismail ${ }^{2}$, Emedya Murniwaty Samsudin ${ }^{1}$, Muhamad Firdaus Abdul Khodir ${ }^{1}$ \\ and Muhammad Aizat Kamarozaman ${ }^{1}$ \\ ${ }^{1}$ Faculty of Civil and Environmental Engineering, Universiti Tun Hussein Onn Malaysia \\ ${ }^{2}$ Department of Design Engineering and Architecture, Universiti Tun Hussein Onn Malaysia
}

\begin{abstract}
Noise control is part of the major requirements to improve the living environment. One of the best methods to reduce noise is by employing sound absorber material into a space. Since traditional sound absorber in the market was believed could cause health problems to human, the need for alternative material is desired. This research intended to utilize waste materials from palm oil empty fruit bunch (EFB) in the production of natural sound absorber for noise control in building. Two parameters were investigated; the fibre length and binder content to determine their effect on sound absorption. Samples were tested using impedance tube using low and high frequencies according to ISO 10534-2:2001. Consequently, both parameters show that different fibre length and binder content affected the ability of the fibre to absorb sound. Results show that the optimum fibre size is in between $2 \mathrm{~mm}$ to $5 \mathrm{~mm}$ length while the optimum amount of binder is between $0 \%$ to $5 \%$ and $15 \%$ from fibre weight. This research has found that the highest Noise Reduction Coefficient (NRC) using $2 \mathrm{~mm}$ to $5 \mathrm{~mm}$ fibre size achieved 0.70 coefficients while the use of optimum amount of binder (particularly Urea Formaldehyde) could obtain 0.75 NRC. The newly develop panels are considered as a good sound absorbent and suitable to use as an alternative material replacing the synthetic absorber.
\end{abstract}

\section{Introduction}

Recently, noise has become one major source of human disturbance. Excessive noise also may deteriorate human physiologically and psychologically [1]. Many people has demanded the solution to this problem. Usually, using sound absorber materials are among the prominent way to solve this problem. However, traditional sound absorber that is extensively used in building compartment made up from synthetic materials including glass and rock wool. These materials are believed to emit carbon dioxide $\left(\mathrm{CO}_{2}\right)$, methane and nitrous oxide in their production [2]. Plus, this usage of materials also gives negative impact to human health and contributes to global warming issues [3].

Therefore, to counter this problem, many researchers have driven their interest by using alternative materials from natural fibre in purpose of replacing synthetic materials as sound absorber. Natural fibres are low in density, have good mechanical properties, easy to be processed, high in stability, health friendly, cheap and reduce the impact to environment during their productions [4]. Previous works have been done by employing natural fibre as sound absorber including sugarcane [5], coconut coir fibre [6], palm oil male flower spikes [7] and mesocarp fibre [8].

Mahzan et al. [9] produce rice-husk waste as reinforced composite and testing using two-microphone transfer function method. $5 \%, 10 \%, 15 \%, 20 \%, 25 \%$ and $30 \%$ of rice-husk added with polyurethane foam (PU). They found that most sample having high SAC value at $250 \mathrm{~Hz}$ with highest SAC 0.899 for $25 \%$ rice-husk sample. Meanwhile, lowest SAC obtained by $15 \%$ ricehusk sample. By calculating the NRC value of the samples, $30 \%$ sample of the rice husk obtained the highest value. They conclude that the rice husk waste has a potential to become a sound absorber, especially at low frequency range.

Ismail et al. [10] utilized arenga pinnata as sound absorber at four distinct thickness, $10 \mathrm{~mm}, 20 \mathrm{~mm}, 30 \mathrm{~mm}$ and $40 \mathrm{~mm}$. Based on the result, the thickness significantly influence the SAC value where thicker sample having high SAC at high frequency region with maximum SAC for $40 \mathrm{~mm}$ sample thickness is 0.88 . Arenga Pinnata fibre was then compared to coir fibre and palm oil fibre. The result indicate that SAC value of Arenga Pinnata was higher compared to coir fibre, around 0.7 to 0.9 but slightly lower than palm oil fibre.

Corresponding author: idalia_nasidi@yahoo.com.my 
Another study by Putra et al. [5] aimed to utilize sugarcane waste as acoustic absorber with different percentages of fibre to binder. Up to $40 \%$ binder, absorption coefficient were not too affected. $3 \mathrm{~g}$ of fibre with composition $70 \%$ of fibre with $30 \%$ of binder show good SAC among the other compositions. The SAC value gained over 0.5 at frequency $1000 \mathrm{~Hz}$ to $4500 \mathrm{~Hz}$. This may be due to denser sample which has greater flow resistivity to create more paths for sound to be absorbed on the sample. By maintaining binder composition, with different amount of fibre $1 \mathrm{~g}$ and $3 \mathrm{~g}$, shows an increasing amount of fibre to enhance the $\mathrm{SAC}$ value. Sample was then compared with three layer of woven cloth absorber. They found that, sugarcane sample were comparable with woven cloth absorber.

Research made by Samsudin et al. [11] differentiated the absorption performance between coir form and dust form of an empty fruit bunch (EFB) at three thickness $6 \mathrm{~mm}, 12 \mathrm{~mm}$ and $18 \mathrm{~mm}$. Thicker sample $(18 \mathrm{~mm})$ for both dust and coir form fibre enhanced the SAC performances as the frequency increased. $18 \mathrm{~mm}$ thick dust form sample had maximum SAC 0.9 at $3250 \mathrm{~Hz}$. While coir form $18 \mathrm{~mm}$ sample gained maximum SAC lower than dust form, 0.62 at $3500 \mathrm{~Hz}$ to $5000 \mathrm{~Hz}$. Dust form showed great performances of absorption compared to coir form caused by the small particle creating highdensity sound absorption material and can easily turn sound energy to heat energy.

Therefore, this paper is discussing the potential of natural fibre waste in Malaysia to be an alternative as acoustic absorber which is the empty fruit bunch (EFB). Even this fibre have been discussed and studied by other researchers, but this research is focusing on the other parameters that are yet to be explored using this kind of natural fibre. The main parameters in this study are the fibre length and percentage of urea formaldehyde (UF) in the sample.

\subsection{Empty Fruit Bunch (EFB)}

Palm oil or known as Elaeis guineensis Jacq. was first planted int Selangor before it became a major plantations in Malaysia. Stated by Malaysian Palm Oil Board (MPOB), most of the states in Malaysia have palm oil plantation area as an agriculture by products with total planted area of 5,642,943 hectares. Subsequently, this oil production generates waste products including empty fruit bunches (EFB), palm kernal shells, mesocarp fruit fibers (MF) oil palm trunks (OPT), oil palm frond (OPF) and palm oil mill efflent (POME).

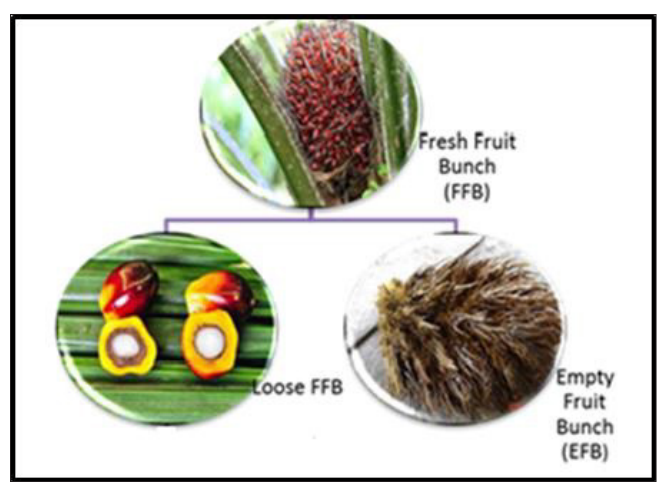

Fig. 1. Breakdown of EFB from FFB
EFB are the residue in solid form that are mostly produced from fresh fruit bunches [12]. Out of $100 \%$ of FFB, $22 \%$ of it is EFB which is the second largest product after sterilization and stripping process where $67 \%$ out of it is POME [13]. EFB that resulted from the extraction process of oil have the potential to be utilized as raw materials for new products in order to reduce the amount of disposal. Traditional way to dispose EFB are by turning it into fuel for production of steam in palm oil mills but faced environmental issues afterwards [14]. Figure 1 shows the breakdowns of EFB from the FFB.

\section{Methodology}

\subsection{Pre-treatment Stage}

EFB fibre supplied by Kulim Plantation, Ladang Tereh Mill located at Kluang Johor. First, fibre was shredded to get into loose form hair like materials. Fibre then soaked in water for 24 hours to remove unwanted dirt or particle retained on fibre. After 24 hours, fibre was soaked with $2 \%$ of Sodium Hydroxide $(\mathrm{NaOH})$ solution for 30 minutes [15]. Finally, fibre was rinsed using clean water and sun dried 2 to 3 days depending on weather to reduce heating rate thus reduce carbon footprint. Controlled moisture content of $10 \%$ [16] was obtained by oven dry fibre for 30 minutes at $110^{\circ} \mathrm{C}$.

\subsection{Fabrication Stage}

Dry fibres were weighted to require proportion. Urea Formaldehyde (UF) used as the binder obtained from S.A. Wood Chemicals Sdn Bhd was sprayed on the fibre using spray air gun to ensure fibres are evenly mixed. Then fibre is fitted into round shape mould, $100 \mathrm{~mm}$ and $28 \mathrm{~mm}$ diameter for Impedance Tube testing with $50 \mathrm{~mm}$ thickness. Hot compression machine was used to compress the panel at $150^{\circ} \mathrm{C}$ for 20 minutes. Figure 2 shows the sample of sound absorber after taken out from the mould.

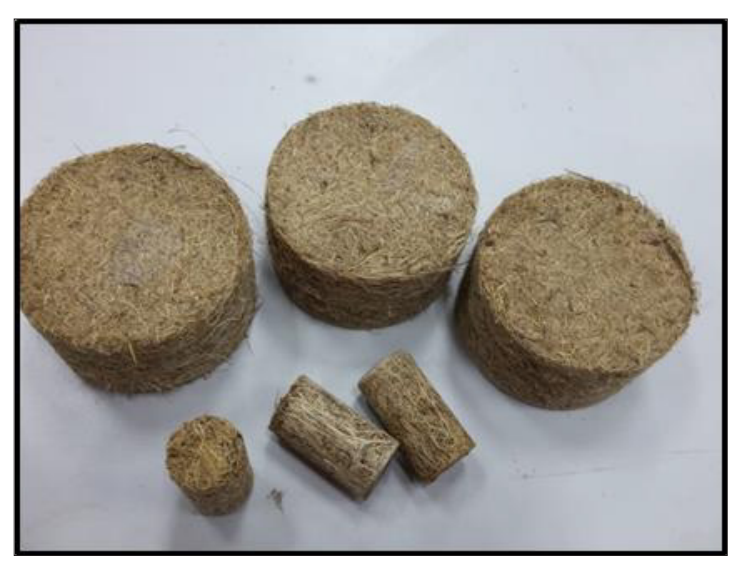

Fig. 2. $100 \mathrm{~mm}$ and $28 \mathrm{~mm}$ diameter sample 
Two parameters were taken throughout these study, fibre length and UF content. For UF content parameter, $0 \%, 5 \%, 10 \%, 15 \%$ and $20 \%$ UF used with $0.4 \mathrm{~g} / \mathrm{cm}^{3}$ target density. While for fibre length parameter, fibre was sieve to get the required length as presented in Table 1 with $65 \%$ solid content used in fabrication stage [17].

Table 1. Length of fibre

\begin{tabular}{|c|c|}
\hline Number & Fibre Length \\
\hline 1 & Retain sieve $15 \mathrm{~mm}$ \\
\hline 2 & Retain sieve $12 \mathrm{~mm}$ \\
\hline 3 & Retain sieve $5 \mathrm{~mm}$ \\
\hline 4 & Retain sieve $2 \mathrm{~mm}$ \\
\hline 5 & Below size $2 \mathrm{~mm}$ \\
\hline
\end{tabular}

\section{Result and Discussion}

The results of impedance tube measurement at high and low frequency from $250 \mathrm{~Hz}$ to $5000 \mathrm{~Hz}$ for empty fruit bunch (EFB) with two distinct parameter, fibre length and UF content are shown in Figure 4 and Figure 5.

Figure 4 shows the SAC result of five different lengths of fibre. Although there were inconsistencies in values all samples demonstrated a uniform pattern of absorption. It can be observed that the sound absorption coefficient increased between frequency $1600 \mathrm{~Hz}$ and $2000 \mathrm{~Hz}$ by shifting the peak from low frequency range

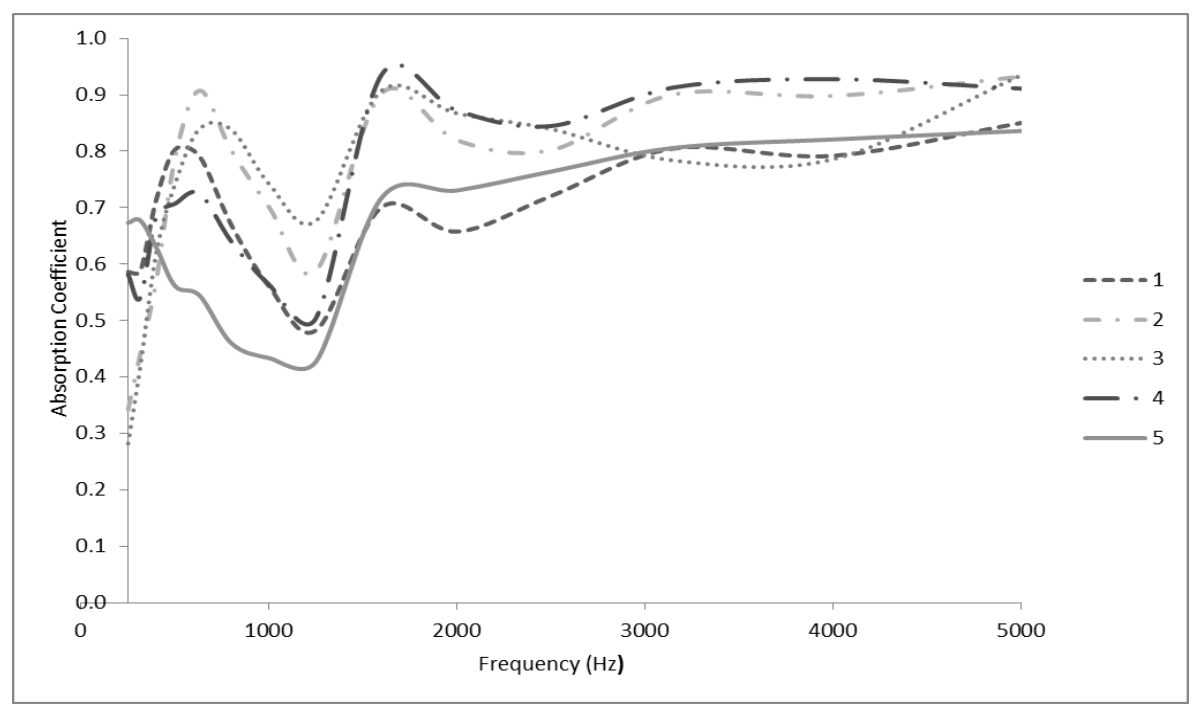

Fig. 4. The sound absorption coefficient with different fibre length

to middle

\subsection{Sound Absorption Measurement}

Sound absorption coefficient of the sample was measured using impedance tube according to ISO10534$2: 2001$, i.e. the transfer-function method [18]. Impedance tube able to measure absorption coefficient of materials using small sample size that was easy to assemble and disassemble [4]. Loudspeaker was placed at the one end of impedance tube and generates broadband, stationary random sound waves while sample placed at the other end. This study used Impedance Tube with AFD1001 software at Building Services Laboratory, Faculty of Civil and Environmental Engineering, Universiti Tun Hussein Onn Malaysia (UTHM). Figure 3 shows Impedance Tube set up.

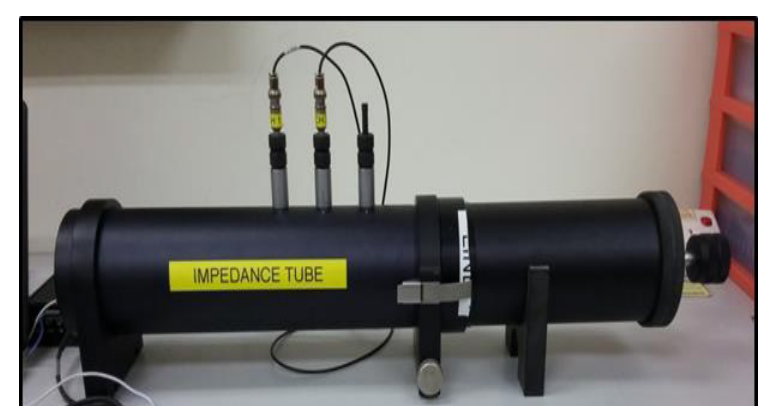

Fig. 3. Impedance Tube frequency range. Sample 2 showed superior performance of SAC at low range frequency while Sample 4 showed a good performance at high range frequency. Highest SAC recorded by Sample 4 with $\alpha=0.937$ at frequency 1600 Hz. Conversely, Sample 5 had least SAC compared to the other sample. Theoretically, these were due to the fibre content on the sample which contained dust form fibre and filled the empty space between the fibre and decreasing the porosity value of the sample that affected the SAC performances. It is found that the fibre length effects the acoustical performances of the material.

Table 2. Density and NRC value for fibre length parameter

\begin{tabular}{|c|c|c|}
\hline Sample & $\begin{array}{c}\text { Density } \\
\left(\mathrm{g} / \mathrm{cm}^{3}\right)\end{array}$ & NRC \\
\hline 1 & 0.39 & 0.65 \\
\hline 2 & 0.39 & 0.65 \\
\hline 3 & 0.41 & 0.65 \\
\hline 4 & 0.44 & 0.70 \\
\hline 5 & 0.42 & 0.60 \\
\hline
\end{tabular}

Table 2 tabulated different density and NRC performances for each sample for fibre length parameter. $\mathrm{NRC}$ is a term that describes the absorption properties of a materials, by averaging value of SAC of materials at frequencies of $250 \mathrm{~Hz}, 500 \mathrm{~Hz}, 1000 \mathrm{~Hz}$ and $2000 \mathrm{~Hz}$ 
and rounded off to the nearest multiple 0.05 [10]. Therefore, NRC value is a number between 0 to 1 which indicated no absorption for zero and full absorption for value one [19]. Generally, density affected the NRC value of sample. Denser structure gave better NRC value from mid to high frequency range but tends to decrease at the low frequency [8].

Urea Formaldehyde (UF) as the binder used in this study with different percentage, $0 \%, 5 \%, 10 \%, 15 \%$ and $20 \%$. From Figure 5, the SAC value for all sample showed a uniform pattern. SAC performance is good above $500 \mathrm{~Hz}$. Sample with highest UF content $(15 \%)$ exhibited a higher SAC with $\alpha=0.957$. All samples had high absorption at the low frequency region, declined at the middle frequency region but then increased at the high frequency region. High content of UF $(20 \%)$ showed the least absorption than other samples. Theoretically, high amount of binder will create less porosity on the sample and reduce the absorption performances of the materials. Jayamani et al. [20] claimed high porosity in sample will cause an increasing friction on the surface where resulted in the dissipation of the sound. percentage of UF increase, the density of samples also increase but significantly decrease the porosity value. According to Bratu et al. [21], high porosity value on sample results in good absorption of the sound wave.

\section{Conclusion}

Empty fruit bunch were studied as an acoustic absorber which have a potential to replace the common synthetic sound absorber materials such as glass wool, rock wool and asbestos. The results indicated that fibre length and binder content plays a role in the improvement of sound absorption performances. High amount of binder and too much small particles of fibre will create less porosity value, thus creating less SAC caused by the sound transmitted on it cannot be changed into heat energy. $15 \%$ of UF percentage as optimum binder with high absorption and resulting good sample without any depreciation on the sample. Therefore, for fibre length parameter, the optimum SAC of EFB is obtained when the fibre length is in between $2 \mathrm{~mm}$ to $5 \mathrm{~mm}$.

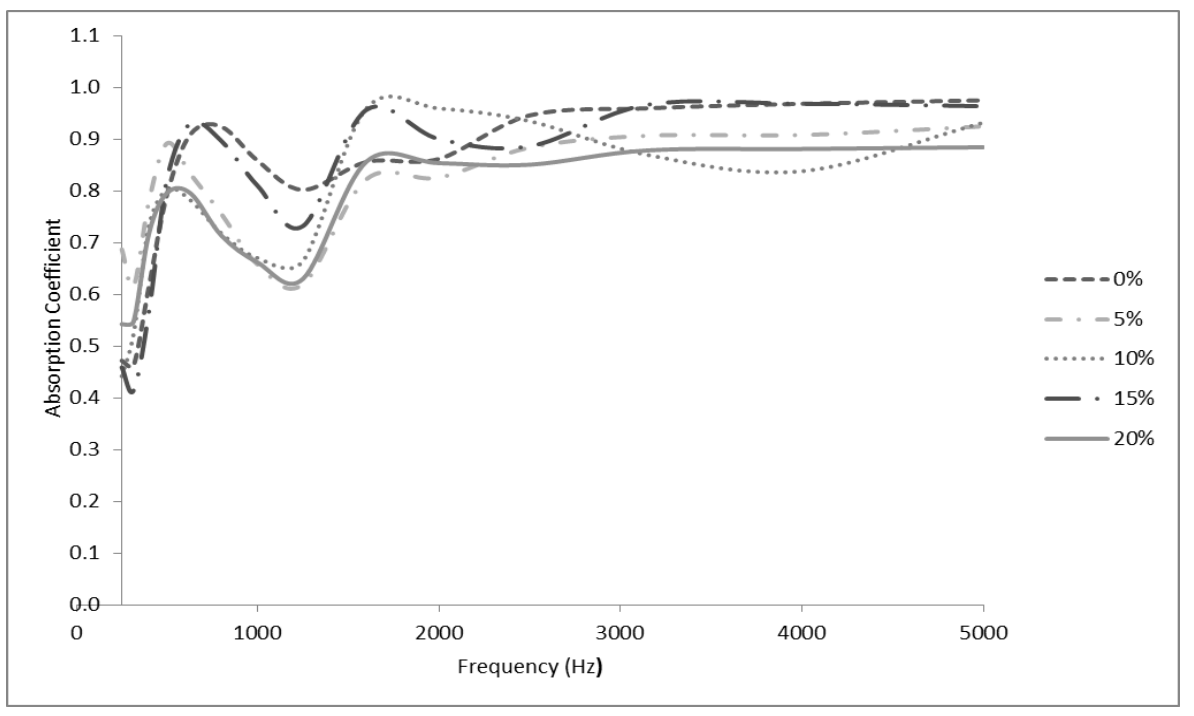

Fig. 5. The sound absorption coefficient with different percentage of UF

UF content parameter having a further analysis by calculating the noise reduction coefficient (NRC) and going through porosity testing.

Table 3. Density, Porosity and NRC value for different UF percentage

\begin{tabular}{|l|l|l|l|}
\hline Sample & $\begin{array}{l}\text { Density } \\
\left(\mathrm{g} / \mathrm{cm}^{3}\right)\end{array}$ & $\begin{array}{l}\text { Porosity } \\
(\%)\end{array}$ & NRC \\
\hline $0 \%$ & 0.24 & 79.95 & 0.75 \\
\hline $5 \%$ & 0.29 & 79.69 & 0.75 \\
\hline $10 \%$ & 0.31 & 76.62 & 0.70 \\
\hline $15 \%$ & 0.32 & 71.30 & 0.75 \\
\hline $20 \%$ & 0.33 & 74.00 & 0.70 \\
\hline
\end{tabular}

Table 3 summarizes the result of density, porosity and NRC value for all samples. All samples show about $70 \%$ of sound is absorbed. It is also indicated that as the
Absorption properties of natural fibres can be increased by controlling the porosity value of newly developed panels. As a green technology product, these innovative absorption panels may have a bright future to replace available synthetic absorber in the markets. However, further research is required to investigate the properties of the natural sound absorber to ensure their safety and strengthness before becoming a commercial acoustic material.

The authors thank Centre for Graduate Studies Universiti Tun Hussein Onn Malaysia (CGS UTHM) for sponsor and financial support in publishing this paper and Office for Research, Innovation, Commercialization and Consultancy Management (ORICC) Universiti Tun Hussein Onn Malaysia, vote U791. 


\section{References}

[1] Fouladi, M. H., Nassir, M. H., Ghassem, M., Shamel, M., Peng, S.Y., Wen, S. Y., Xin, P. Z. \& Nor, M. J. M. (2013). Utilizing Malaysian Natural Fibers as Sound Absorber, Modeling and Measurement Methods for Acoustic Waves and for Acoustic Microdevices, ISBN: 978-953-511189-4

[2] Arenas, J.P. and Crocker, M.J. (2010) Recent Trends in Porous Sound-Absorbing Materials. Sound \& Vibration, 44, 12-17

[3] Asdrubali, F. (2007). Green and sustainable materials for noise control in buildings. $19^{\text {th }}$ International Congress on Acoustic Madrid, (September 2007)

[4] Berardi, U., Iannace, G., \& Di, M. (2016). Challenges and Solutions in Acoustical Measurements and Design: Paper ICA2016-238 Characterization of sheep wool panels for room acoustic applications Characterization of sheep wool panels for room acoustic applications

[5] Putra, A., Abdullah, Y., Efendy, H., Farid, W.M., Ayob, M.R., \& Py, M. S. (2013). Utilizing Sugarcane Wasted Fibers As A Sustainable Acoustic Absorber, Procedia Engineering, 53, $632-638$

[6] Nor, M. J. M., Ayub, M., Zulkifli, R., Amin, N. \& Fouladi, M. H. (2010). Effect of Different Factors on the Acoustic Absorption of Coir Fiber, Journal of Applied Sciences, 10(22), 2887-2892

[7] Masrol, S. R., Rosdin, M. K. R. \& Ibrahim, M. N. (2013). Sound Absorption Characteristics of Palm Oil Male Flower Spikes Fiber Reinforced Composite. International Confrence on Mechanical Engineering Research (ICMER2013), 1-3

[8] Latif, H. A., Yahya, M. N., Zaman, I., Sambu, M., \& Ghazali, M. I. (2016). The Influence of Physical Properties and Different Percentage of The Oil Palm Mesocarp Natural Fiber, 11(4), 2462-2466

[9] Mahzan, S., Zaidi, A. M. A., Yahya, M. N., \& Ismail, M. (2009). Investigation on Sound Absorption of Rice-Husk Reinforced Composite. In: Proceedings of MUCEET2009 Malaysian Technical Universities Conference on Engineering and Technology

[10] Ismail, L., Ghazali, M. I., Mahzan, S., Mujahid, A., \& Zaidi, A. (2010). Sound Absorption of Arenga Pinnata Natural Fiber, 4(7), 804-806

[11] Samsudin, E. M., Ismail, L. H., \& Kadir, A. A. (2016). Comparison On Acoustic Performance Between Dust And Coir Form Empty Fruit Bunches (Efb) As Sound Absorption Material, Jurnal Teknologi, 78 (5), 191-196

[12] Piarpuzán, D., Quintero, J. A., \& Cardona, C. A. (2011). Empty fruit bunches from oil palm as a potential raw material for fuel ethanol production. Biomass and Bioenergy.
[13] Abdullah, N., \& Sulaiman, F. (2013). The Oil Palm Wastes in Malaysia. Biomass Now Sustainable Growth and Use, 75-100

[14] Kadir, A. A., Azian, N., Zahari, M., \& Mard, N. A. (2013). Utilization of Palm Oil Waste into Fired Clay Brick, 7, 3826-3834

[15] Izani, M. A. N., Paridah, M. T., Astimar A. A., Nor, M. M. Y. \& Anwar, U. M. K. (2012). Mechanical and dimensional stability of medium density fibreboard produced from treated oil empty fruit bunch, Journal of Applied Science, 12(6), 561-567

[16] Karlinasari, L., Hermawan, D., Maddu, A., Martianto, B., Lucky, I. K., Nugroho, N. \& Hadi, Y. S. (2012). Acoustical Properties of Particleboards Made from Betung Bamboo (Dendrocalamus asper) As Building Construction Material, 7(4), 5700-5709

[17] Seddeq, H. S., Aly, N. M., A, A. M., \& Elshakanekery, M. (2013). Investigation on sound absorption properties for recycled fibrous materials. Journal of Industrial Textiles, 43(1), 56-73. doi:10.1177/1528083712446956

[18] British Standards Institution (2001). Acoustics Determination of sound absorption coefficient and impedance impedance tubes-Part 2:Transfer-function method. United Kingdom: BS EN ISO 10534-2:2001 Incorporating Amendment No. 1 to BS ISO 10534-2:1998 (renumbers the BS ISO as BS EN ISO 10534-2:2001)

[19] Lechner, N. (2012). Plumbing, Electricity, Acoustics Sustainable Design Methods for Architecture. United States of America: John wiley \& Sons, Inc

[20] Jayamani, E., Hamdan, S., Rahman, M., Soon, K., and Bakri, M. (2014). Processing and Characterization of Epoxy/Luffa Composites: Investigation on Chemical Treatment of Fibers on Mechanical and Acoustical Properties. BioResources, 9(3), 5542-5556

[21] Bratu, M., Dumitrescu, O., Vasile, O., Cristea, A. C., \& Muntean, M. (2014). Research On The Sound-Absorbing Properties Of New Composite Materials With Some Wastes, Romania Journal of Material, 44(2), 160-168. 